\title{
Odontoid screw fixation for fresh and remote fractures
}

\author{
Ganesh Rao, Ronald I. Apfelbaum \\ Department of Neurosurgery, University of Utah, Salt Lake City, Utah - 84132, USA
}

\begin{abstract}
Fractures of the odontoid process are common, accounting for $10 \%$ to $20 \%$ of all cervical spine fractures. Odontoid process fractures are classified into three types depending on the location of the fracture line. Various treatment options are available for each of these fracture types and include application of a cervical orthosis, direct anterior screw fixation, and posterior cervical fusion. If a patient requires surgical treatment of an odontoid process fracture, the timing of treatment may affect fusion rates, particularly if direct anterior odontoid screw fixation is selected as the treatment method. For example, type II odontoid fractures treated within the first 6 months of injury with direct anterior odontoid screw fixation have an $88 \%$ fusion rate, whereas fractures treated after 18 months have only a $25 \%$ fusion rate. In this review, we discuss the etiology, biomechanics, diagnosis, and treatment (including factors affecting fusion such as timing and fracture orientation) options available for odontoid process fractures.
\end{abstract}

Key Words: Bone screws; fracture fixation or spinal fractures/surgery; odontoid process

\section{Introduction}

Fractures of the odontoid process (the dens) of the axis account for $10-20 \%$ of acute cervical spine fractures. ${ }^{[1-8]}$ Certain types of odontoid process fractures can lead to gross instability of the atlantoaxial complex and present a significant risk for a potentially catastrophic spinal cord injury. ${ }^{[9]}$ The treatment of odontoid process fractures remains controversial and ranges from external orthosis to various internal fixation techniques. This paper will review the treatment options for fresh and remote dens fractures.

\section{Fractures of the odontoid}

Anderson and D'Alonzo classified fractures of the odontoid process into three types. ${ }^{[10]}$ Type I fractures involve the apical portion of the dens and are typically considered stable, although Scott et al. ${ }^{[11]}$ suggested they may represent an avulsion of the alar ligaments and thus result in instability. If instability is suspected with a type I fracture, flexion/extension x-rays may reveal whether there is abnormal motion of the atlantoaxial joint.

Type II fractures involve the neck of the odontoid process (where it joins the body of $\mathrm{C} 2$ ). These are the most common odontoid fractures and are unstable. The fractured odontoid process may be displaced anteriorly or posteriorly relative to the body of $\mathrm{C} 2$.

Type III fractures extend into the body of C2. True type III fractures are typically managed with external immobilization, which is often successful, although they are also amenable to surgery. ${ }^{[12]}$ Some odontoid fractures are comminuted at the base of the dens and are associated with free fracture fragments. This subset of fractures, designated type IIA, ${ }^{[52]}$ is less likely to be treated successfully with external immobilization.

Type II fractures have been further classified, based on the direction of the fracture line, as anterior oblique, posterior oblique, or horizontal fractures (Figure 1). ${ }^{[1]}$ The fracture line of an anterior oblique fracture slopes superiorly from posterior to anterior, whereas a posterior oblique fracture slopes superiorly from anterior to posterior. A horizontal fracture slopes minimally or not at all. The slope of the fracture is an important consideration regarding treatment; for example, an anterior oblique fracture has a lower fusion rate when treated with a direct anterior odontoid screw. $^{[1]}$

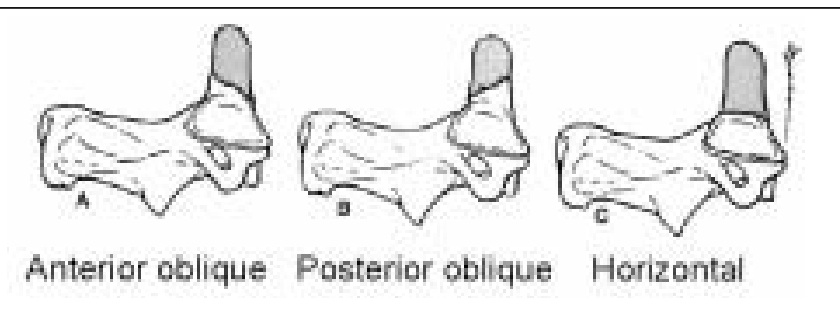

Figure 1: Illustration of the three types of fracture lines of type II odontoid fractures 
Evaluation of an odontoid fracture generally begins with plain x-rays, including lateral, anterior-posterior (AP), and open-mouth radiographs of the cervical spine. If an odontoid fracture is suspected, thin-section computerized tomography (CT) with reconstructions in the coronal and sagittal planes is recommended for further evaluation. ${ }^{[14,15]}$ Magnetic resonance imaging may also be used to assess the integrity of the transverse ligament. ${ }^{[14,16]}$

\section{Mortality and neurological injury}

Estimates of mortality from dens fractures at the time of the injury are $25 \%-40 \%{ }^{[17,18]}$ Survivors of the injury are usually neurologically intact, although Anderson and D'Alonzo ${ }^{[10]}$ found that $15(25 \%)$ of 60 patients had various neurologic deficits, including Brown-Sequard syndrome, mild upper-extremity weakness, hyper-reflexia of the lower extremities, and decreased occipital sensation. Delayed onset of symptoms has also been reported..$^{[9,19]}$ The most common presenting symptom with an undiagnosed odontoid fracture is neck pain, although patients may also complain of hand weakness and lower extremity "stiffness." ${ }^{[9]}$ These fractures must be treated because the potential for ongoing neurologic compromise is well known. ${ }^{[19-22]}$

\section{Treatment of odontoid process fractures Conservative management}

Type I and Type III fractures have been treated with external immobilization with a high degree of success. Julien et al. ${ }^{[23]}$ performed an evidence-based analysis of the literature to evaluate the management of odontoid fractures. Halo/Minerva fixation or cervical traction followed by immobilization in a rigid cervical collar resulted in fusion of all type I odontoid fractures and $84-88 \%$ of type III fractures. ${ }^{[23,24]}$

Cervical traction followed by immobilization is not the most effective treatment of type II odontoid fractures. Julien et al. ${ }^{[23]}$ reported that treatment of type II fractures with cervical traction/ cervical collar resulted in a fusion rate of only $57 \%$. Management with a halo-type orthosis has a variable nonunion rate from $7 \%{ }^{[25]}$ to $100 \% .{ }^{[26]}$ Nonunion rates varying from $21 \%$ to $45 \%$ have been reported often. ${ }^{[3,4,27-30]}$

\section{Posterior fusion}

Historically, posterior cervical fusion was the primary operative alternative when external immobilization failed or was considered unsuitable. Wiring techniques, including those described by Brooks, Gallie, and later Dickman and Sonntag, have been used to achieve posterior cervical fusion. Brooks' technique involves two wedge bone grafts secured between C1 and C2 with sublaminar wiring. ${ }^{[31]}$ In Gallie's technique, a superior notch in the spinous process of $\mathrm{C} 2$ holds the $H$-shaped on-lay graft more securely in place, and the graft is secured with a wire that is only sublaminar at C1 ${ }^{[32]}$ Finally, Dickman and Sonntag described an atlantoaxial arthrodesis secured with a sublaminar wire at C1 that incorporated an iliac crest strut-graft between the posterior arches of $\mathrm{C} 1$ and $\mathrm{C} 2$ secured with wire around the base of the spinous process of the axis. ${ }^{[33]}$
In 1992, Jeanneret and Mager ${ }^{[34]}$ recommended the use of transarticular screws rather than a Gallie or Brooks fusion alone. They reported $100 \%$ fusion and only one complication with $\mathrm{C} 1$ C2 transarticular screw fixation in addition to posterior fusion. Dickman et al. ${ }^{[35]}$ reported a $98 \%$ fusion rate for patients undergoing C1-2 transarticular screw fixation and an $86 \%$ fusion rate for patients undergoing $\mathrm{C} 1-2$ fixation with only wires and arthrodesis.

Fusion rates for transarticular screws are almost $100 \% .^{[35-39]}$ When the anatomy is favorable, this technique is generally preferred because of excellent results. Posterior fusion may be preferred in patients who have a comminuted type II or III fracture or an associated unstable Jefferson fracture, or who cannot tolerate external immobilization.

Several issues must be considered concerning C1-2 posterior fusion. The passage of cables or wires, especially C2 sublaminar wires, into the spinal canal may injure neural elements. Structural bone grafting should always be used to achieve solid fusion, which is critical to achieving long-term stability, as hardware is unreliable for long-term stability. If an intact posterior arch of $\mathrm{C} 1$ is not present, alternative fusion techniques such as decortication and bone packing into the $\mathrm{C} 1-2$ joint or the lasso technique can be applied. ${ }^{[40]} \mathrm{C} 1-2$ joint fusion eliminates $50 \%$ of the rotation of the head, a significant loss of motion. Consequently, a technique for treating odontoid fractures, anterior odontoid screw fixation, has been developed to preserve the normal motion of the C1-2 joint.

\section{Anterior fusion}

Beginning with Nakanishi ${ }^{[41]}$ in 1980 , several authors have described the surgical technique for anterior odontoid screw fixation. ${ }^{[2,42-46]}$ The technique has gained increased acceptance as instrumentation has improved, advances in minimally invasive approaches have been developed, and improvements in fluoroscopic guidance have been made. ${ }^{[47,48]}$ Direct anterior screw fixation is an osteosynthetic technique that provides immediate spinal stabilization, preserves rotation of $\mathrm{C} 1$ on $\mathrm{C} 2$, and allows rapid return to normal lifestyle. ${ }^{[45,49]}$ Retention of full range of motion has been reported to be as high as $83 \%{ }^{[50]}$

\section{Anterior odontoid screw fixation Surgical technique}

The patient is positioned supine with a folded blanket under the shoulder to allow for neck extension and under the head to maintain neutral position until lateral fluoroscopy is obtained. The extension required for standard intubation may put the patient at risk, thus care is required when intubating the patient. Holter traction ( $5 \mathrm{lbs}$.) is applied, and under fluoroscopy, the padding underneath the patient's head is removed to provide extension except in the case of a retrolisthesed odontoid fragment.

Bipolar fluoroscopy is used to monitor head positioning and alignment of the odontoid. Figure 2 demonstrates the positioning of the patient and orientation of the fluoroscopes for the procedure. The AP view is obtained transorally, with a radiolucent prop (e.g., a cork) used to keep the mouth open. The lateral view is achieved 
by placing a second fluoroscope with the $\mathrm{C}$-arm arc $30^{\circ}$ above the horizontal.

The initial approach to the spine at the C5 level is the same as for an anterior cervical discectomy (Figure 3). Upon exposure of the prevertebral space, the carotid lies laterally and the trachea and esophagus medially. The longus colli muscles are elevated over about $1 \frac{1}{2} 2$ vertebrae, and a sharp-bladed special self-retaining retractor is inserted below these muscles. The loose prevertebral areolar tissue is opened by sweeping a peanut dissector side-toside to prepare a working tunnel to the C1-C2 level (confirmed fluoroscopically). A special self-retaining retractor, attached to the lateral retractor base, maintains a working tunnel up to the caudal edge of $\mathrm{C} 2$.

Under fluoroscopy, a K-wire is positioned on the anterior, inferior lip of $\mathrm{C} 2$ at the entrance site for the fixation screw. The K-wire is placed in the midline or 3-4 $\mathrm{mm}$ from the midline for one or two screws, respectively. An 8-mm hollow drill is placed over the Kwire and rotated manually to create a shallow trough in the ventral body of $\mathrm{C} 3$ for the guide tube system and to incise the $\mathrm{C} 2-3$ annulus without cutting into the C2 body (Figure 4). The drill guide tube



Figure 2: Patient positioning for direct anterior odontoid screw fixation

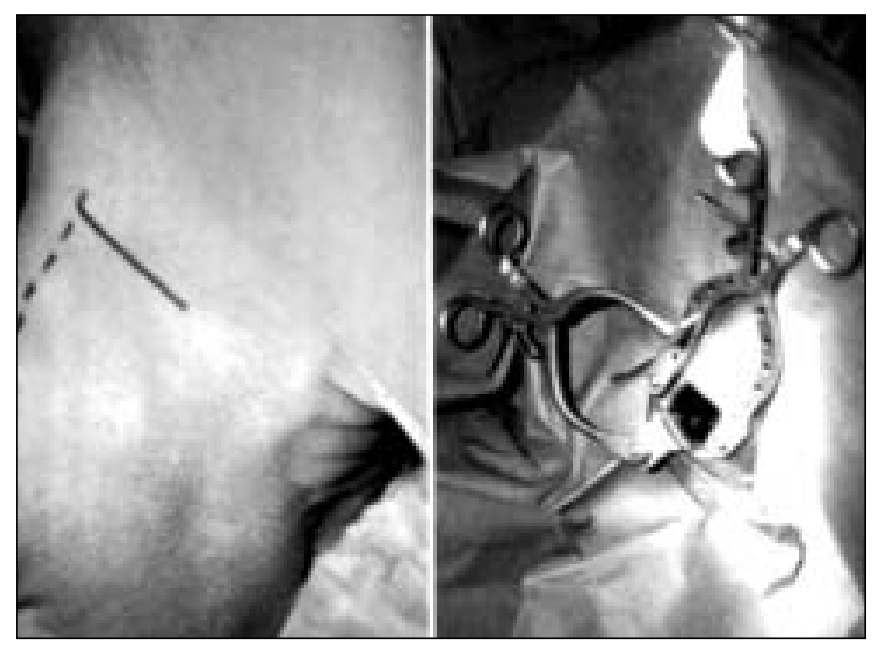

Figure 3: Incision and retractor placement for direct anterior odontoid screw fixation system, with inner and outer guide tubes, is "walked" up until the spikes on the outer tube are over the body of C3 (Figure 5). These are set into the body to fix the guide tube system using an impactor. The inner guide tube is advanced to the anterior, inferior edge of $\mathrm{C} 2$ in the trough and the $\mathrm{K}$-wire is removed. With the guide tube firmly engaged in the body of C3, C2 alignment is optimized using fluoroscopic guidance by pushing $\mathrm{C} 2$ and $\mathrm{C} 3$ dorsally relative to the odontoid-C1 complex or pulling $\mathrm{C} 2$ and $\mathrm{C} 3$ ventrally. In the case of a retrolisthesed odontoid fragment, realignment can be achieved and maintained while the patient's head is gradually extended as the padding under the head is removed.

After satisfactory alignment is obtained, a pilot hole is drilled through C2 to the apex of the odontoid (Figure 6). Penetration of the distal cortex is important for screw placement. The angle of the drill is coaxial with the odontoid process and tangential to the dura, so injury to the spinal cord is easily avoided. Repeated fluoroscopic checks of the trajectory are necessary to control the drilling process (Figure 7). The pilot hole is then tapped, and a lag screw is inserted through the guide tube using a special screwdriver designed to hold the screw (Figure 8A). The lag screw is selected based on the measured drilled depth and is typically $4 \mathrm{~mm}$ in diameter. The screw is not threaded proximally to allow the odontoid fragment to be pulled down to the body of $\mathrm{C} 2$ (Figure $8 \mathrm{~B}$ ). If a second screw is to be placed these steps are repeated. The second screw can be fully threaded as no additional lagging effect is anticipated (Figure 8C).

\section{Considerations of odontoid screw fixation}

Various parameters have been identified as predictors of failure for fusion of type II odontoid fractures. ${ }^{[27,29,51,52]}$ The degree of displacement of the dens fracture has been associated with nonunion. Generally, displacement less than $4 \mathrm{~mm}$ has been associated with improved fusion rates, whereas displacement greater than $6 \mathrm{~mm}$ is associated with higher rates of nonunion. ${ }^{[5,27,53]}$

Age is another important factor in the successful healing of

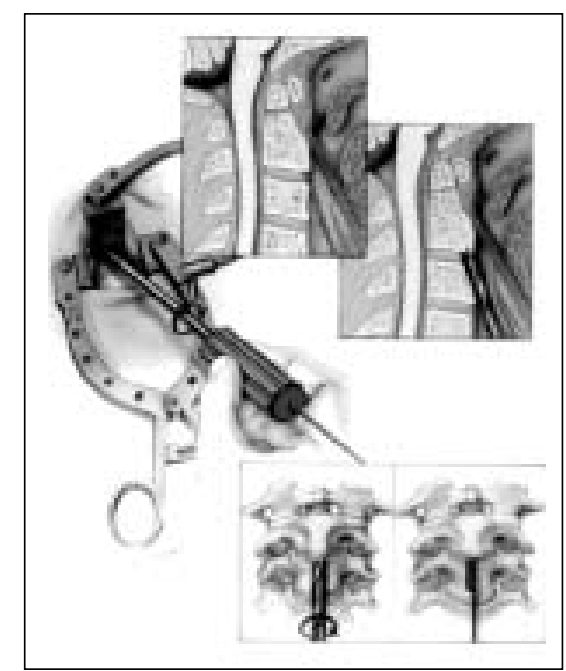

Figure 4: Placement of the K-wire into the body of C2. The K-wire serves as a guide for the hollow hand drill that is used to create a trough through the ventral body of $\mathrm{C} 3$ and to incise the $\mathrm{C2}-3$ annulus 


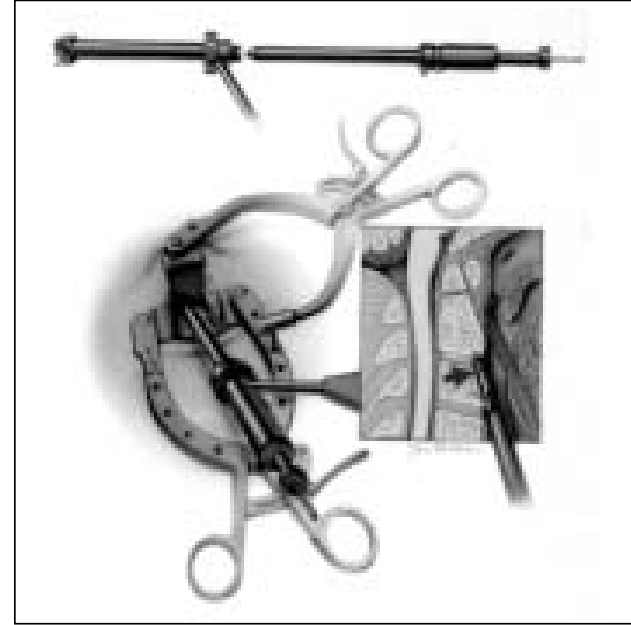

Figure 5: Illustration demonstrating the mating of the inner and outer guide tubes and the insertion of the spikes into the body of $\mathrm{C} 3$.

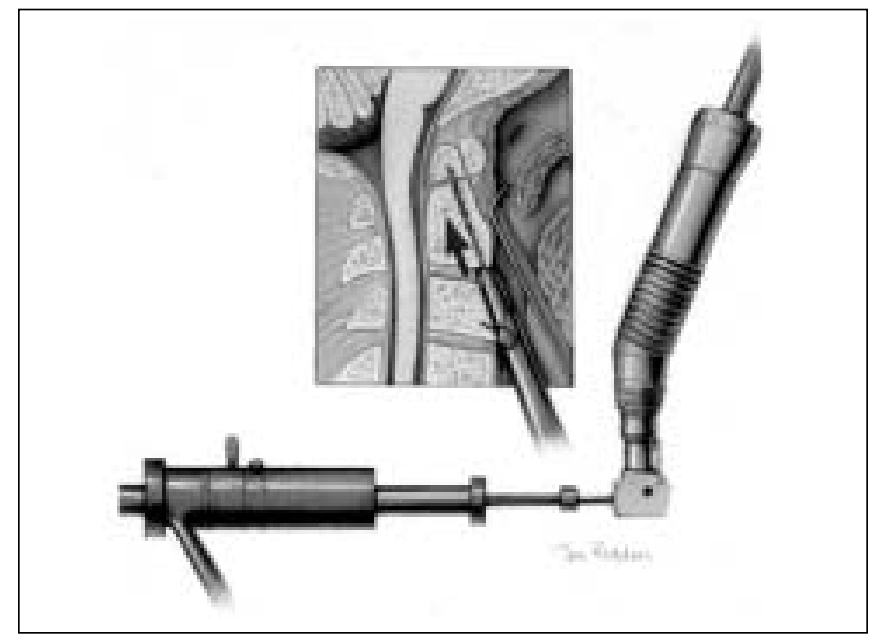

Figure 6: Drilling of the pilot hole into C2

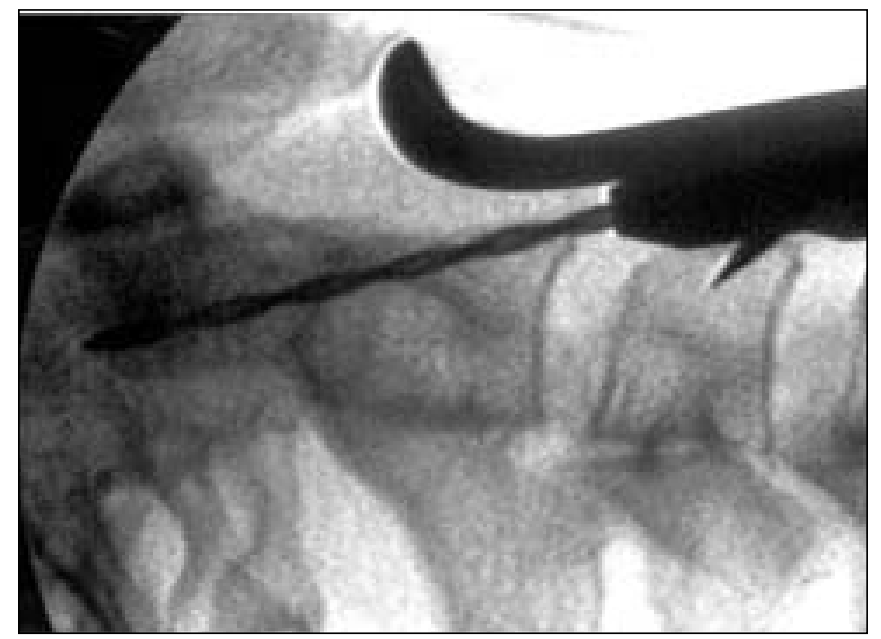

Figure 7: Fluoroscopic image of the drill into the body of $\mathrm{C} 2$ and crossing into the fractured odontoid process odontoid fractures. Children with odontoid process fractures generally achieve stable fusion with halo immobilization, ${ }^{[54-56]}$ whereas adult patients fare poorly with external immobilization ${ }^{[57-}$ ${ }^{61]}$ In a case-control study of 33 patients, individuals over 50 years had a nonunion rate 21 times higher than those under 50 when treated with halo immobilization.

The issue of whether to place one or two odontoid screws is controversial. Two-screw constructs have been advocated to prevent an axis of rotation around a single screw. In some patients, however, the odontoid process is not large enough to accommodate two screws. ${ }^{[62]}$ We generally advocate placement of two screws, if possible, although there appears to be similar clinical success with both the one- and two-screw constructs. ${ }^{[1,63]}$

For patients who present with recent injury and no concomitant transverse ligament rupture, the senior author (RLA) prefers using direct anterior screw fixation to retain rotation of $\mathrm{C} 1$ on $\mathrm{C} 2$. $^{[1]}$ The procedure is well tolerated, does not rely on bone graft harvest, and generally requires no other postoperative treatment (e.g., cervical collar). The fusion rate is $88 \%$ when the surgery is performed within the first 6 months of injury but drops to $25 \%$ for remote fractures (i.e., >18 months following injury). ${ }^{[1]}$ Therefore, it is clear that the timing of surgery is important. If a patient fails external immobilization and is within 6 months of the injury, anterior odontoid screw placement is still an option.

\section{Surgical technique for C1-2 transarticular screws}

Because remote type II fractures have a higher rate of nonunion than recent fractures, they usually should be treated with posterior C1-2 fixation and fusion. Similarly, when atlantoaxial instability is not remediable by placement of an odontoid screw, posterior cervical fusion is indicated. When favorable anatomy exists, placement of C1-C2 transarticular screws may be used for stabilization.

Several important anatomic elements must be evaluated in patients requiring posterior fusion. Poor bone quality, although not an absolute contraindication, may require external fixation in



Figure 8: (A) Illustration of the lag screw prior to its engagement of the fractured odontoid process. Final AP and lateral fluoroscopic images of a single (B) and two (C) odontoid screws 
addition to internal fixation. For C1-C2 transarticular screw fixation, an adequate pathway for the screw trajectory is essential. A vertebral artery that courses into the pars of $\mathrm{C} 2$ may interfere with potential screw trajectory, with obvious potentially disastrous neurologic effects. This is best evaluated using thin-section CT scans reconstructed in the sagittal plane. Multiplanar reconstructions or the use of a stereotaxic workstation can assist in defining a safe trajectory and the latter can provide invaluable intraoperative guidance as well.

A technique for posterior C1-2 fusion with polyaxial screwand-rod fixation minimizes the risk of injury to the vertebral artery and is especially valuable when posterior wiring techniques cannot be performed such as when the posterior elements are deficient. ${ }^{[64]}$ This is a modification of a technique described way back in 1994 by Goel and Laheri. ${ }^{[65]}$ The earlier description by Goel et al involves uniaxial screws in the lateral mass of $\mathrm{C} 1$ and pedicle of $\mathrm{C} 2$ anchored to plates bilaterally. The authors later presented the application of this technique in cases of trauma and odontoid non-unions. ${ }^{[6,67]}$

Once the criteria for transarticular screw placement have been met, the patient is positioned prone with the head supported in a pin-head holder (Figure 9). The patient is placed in a "military posture" with the lower cervical spine extended while slightly flexing and posteriorly translating the skull and C1. Lateral fluoroseopic images are used to optimize the C1-2 position. Extension of the lower cervical spine and flexion of the occiput will usually reduce the atlantoaxial subluxation by posteriorly translating the atlas.

A midline dorsal incision from the inion to $\mathrm{C} 3$ exposes the posterior elements of $\mathrm{C} 1$ and $\mathrm{C} 2$ and the $\mathrm{C} 2$ isthmus and associated venous complex. The lamina of $\mathrm{C} 2$ is dissected free of soft tissue to the facet joints of C2 and C3 (Figure 10). Once the anatomic structures have been adequately exposed, fixation screws are placed just rostral to the C2-C3 facet joint and aligned with the pars interarticularis. The appropriate trajectory for the screw is determined by aligning a drill or K-wire fluoroscopically to the

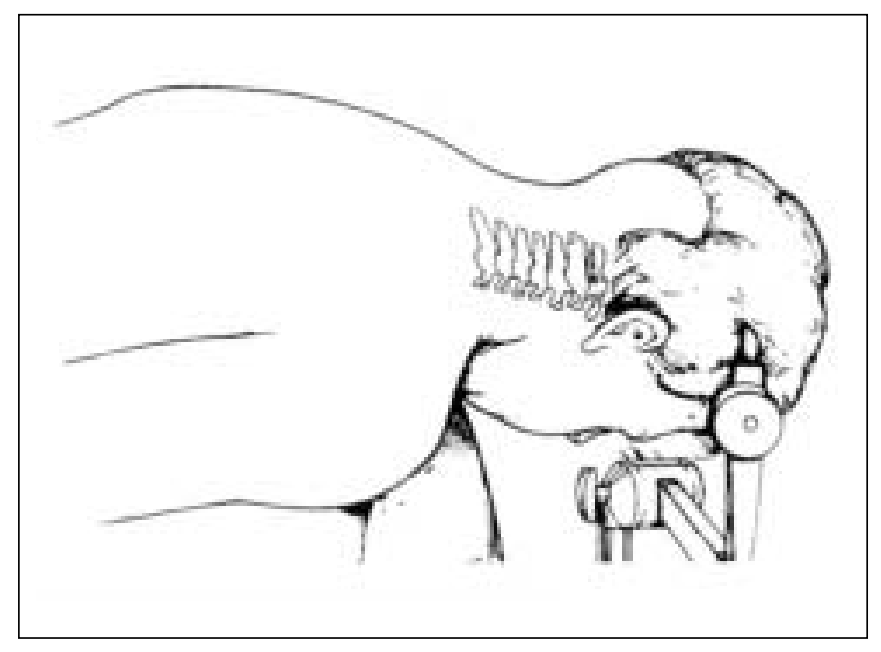

Figure 9: Illustration depicting positioning for $\mathbf{C 1 - 2}$ transarticular screw fixation desired screw position. The screw should pass through the isthmus of $\mathrm{C} 2$ and cross the C1-2 articulation into the lateral mass of $\mathrm{C} 1$. Imaging also allows the surgeon to determine the incision sites for placement of the drill. Initial 1.5-cm stab incisions 1-2 $\mathrm{cm}$ off the midline, usually in the region of $\mathrm{T} 2$, are carried down to the dorsal fascia. As with odontoid screw fixation, a guide tube is used. A smooth tube fitted with a conical-tipped obturator is passed from the skin incision up to the drill entry site at the C2-C3 junction (Figure 11) by pressing firmly in a rostral direction and rotating the instrument to advance it into the surgical field. After the guide tube is placed, the obturator is removed and an awl is placed into the guide tube to begin a starting hole in the $\mathrm{C} 2$ lamina.

The drill must be passed carefully within the limits of the pars interarticularis using fluoroseopic confirmation of the trajectory. The trajectory should be low-angled just under the dorsum of the pars to engage the maximum amount of $\mathrm{C} 1$ lateral mass (Figure $12 \mathrm{~A}$ ) and to keep the drill above the vertebral artery. On the lateral fluoroscopic image, the ventral arch of $\mathrm{C} 1$ is a helpful target for the drill. The depth of the pilot hole is noted on the calibrated drill guide (Figure 12B) and the images are stored on the fluoroscope. The drill is removed, the hole is tapped, and the fully threaded screw is placed (Figure 13A-C). Fluoroscopy is also used to optimize the vertebral alignment before crossing the C1-C2 articulation.

The same steps are repeated for placement of the contralateral screw. Brisk arterial bleeding after drilling the pilot hole may indicate vertebral artery compromise. If this occurs after drilling the first hole, we recommend placing the first screw for fixation and a tamponade effect but forgoing placement of the second screw. Postoperative imaging (e.g., angiography) is suggested to determine the status of the vertebral artery.

After both screws have been placed, bone grafting is placed to provide long-term stability. The screws initially provide fixation, but bone fusion is key to long-term stability. If fusion fails to occur, the hardware will ultimately fail. The Sonntag-Dickman construct using an interpositional bicortical iliac crest is typically used ${ }^{[33]}$ although other constructs may be used. ${ }^{[31]}$ Decortication is necessary for the surfaces of the $\mathrm{C} 1$ and $\mathrm{C} 2$ lamina that will be apposed to the graft. The mating cortical surfaces are denuded using a high-speed drill. The graft is contoured to fit snugly within the graft site. A braided titanium cable is placed in a sub-laminar fashion at $\mathrm{C} 1$ and around the spinous process of $\mathrm{C} 2$ to secure the graft, which is thus "sandwiched" between two layers of cable (Figure 14A,B). Additional bone chips or shavings may be placed around the graft for enhancement of fusion (Figure 15A-C).

Chronic dens fractures may also result in ventral compression of the spinal cord, which can result in progressive spinal cord damage. ${ }^{[9,21,69]}$ Therefore, it is important to realign the spine before posterior fusion. If realignment is not possible, transoral odontoid resection to decompress neural element preceding posterior fusion is indicated. ${ }^{[9,13,19,68,69]}$ However, although this procedure has become more common, it is technically demanding. ${ }^{[67]}$ 


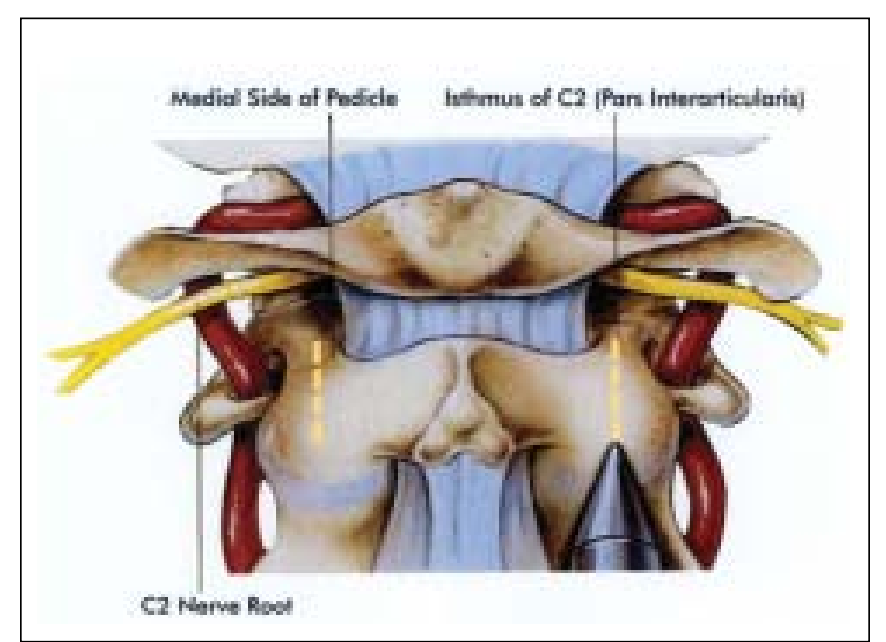

Figure 10: Illustration showing the pars interarticularis and the exposed facet joints of C2-3

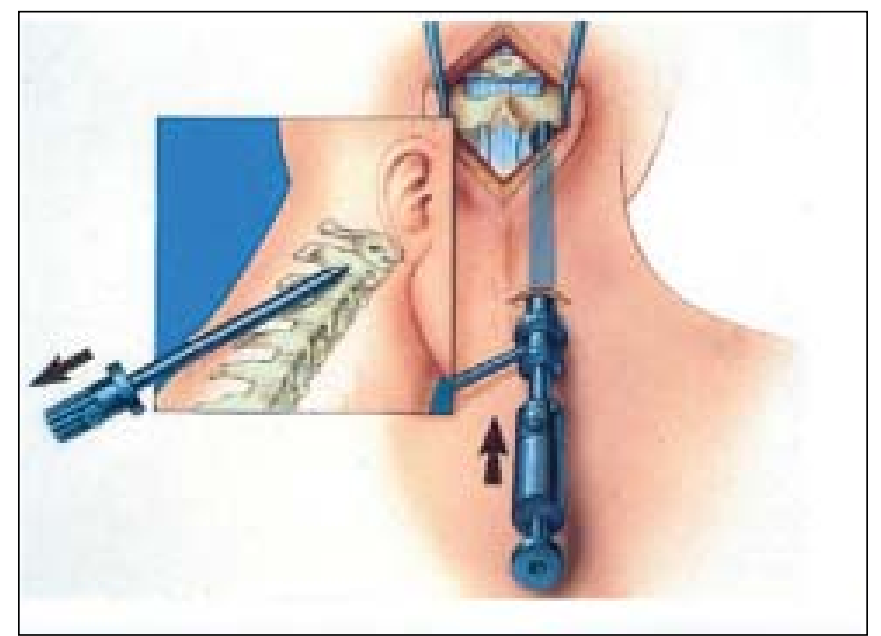

Figure 11: Placement of the drill guide tube with a conical obturator passed from a stab incision in the upper back to the entry point for the C1-2 transarticular screw at the C2-3 junction

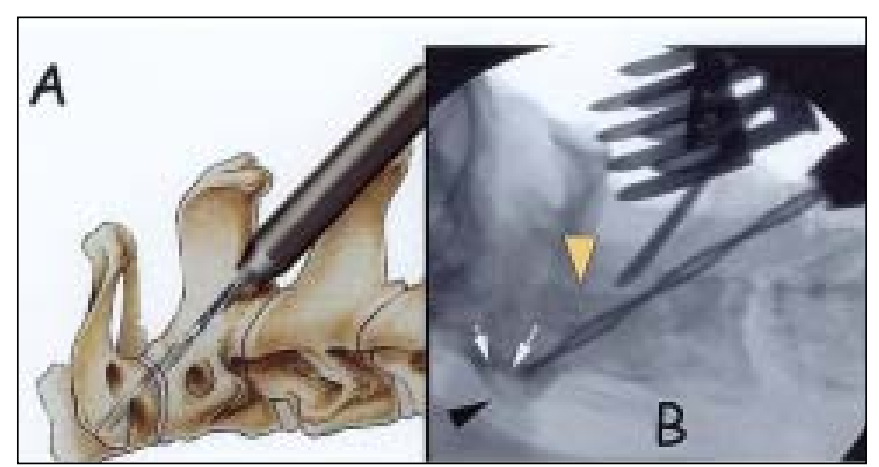

Figure 12: (A) Illustration of the trajectory for drilling. (B)

Fluoroscopic view of the drilling process. The black arrowhead indicates the anterior arch of $\mathrm{C} 1$. The white arrows indicate the edge of the lateral mass of $\mathrm{C} 1$, and the yellow arrow indicates the $\mathrm{C1}_{1-2}$ joint

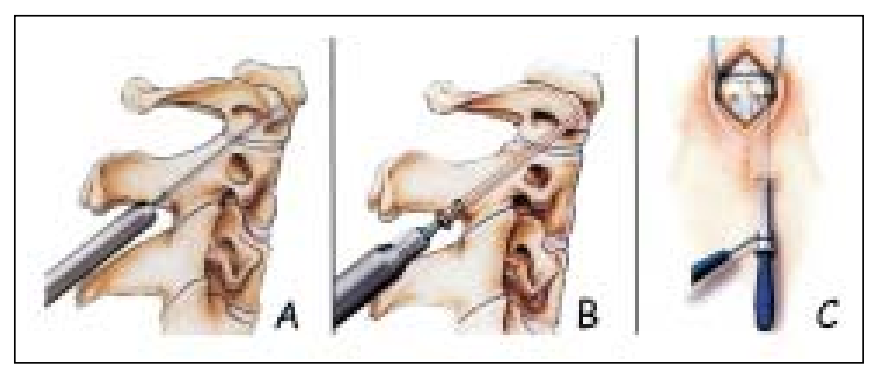

Figure 13: (A) Illustration showing the drill at its full depth. (B) Placement of the screw across the C1-2 joint. (C) Placement of the screw through the drill guide



Figure 14: Lateral (A) and posterior (B) views of the graft held in place by a braided titanium cable

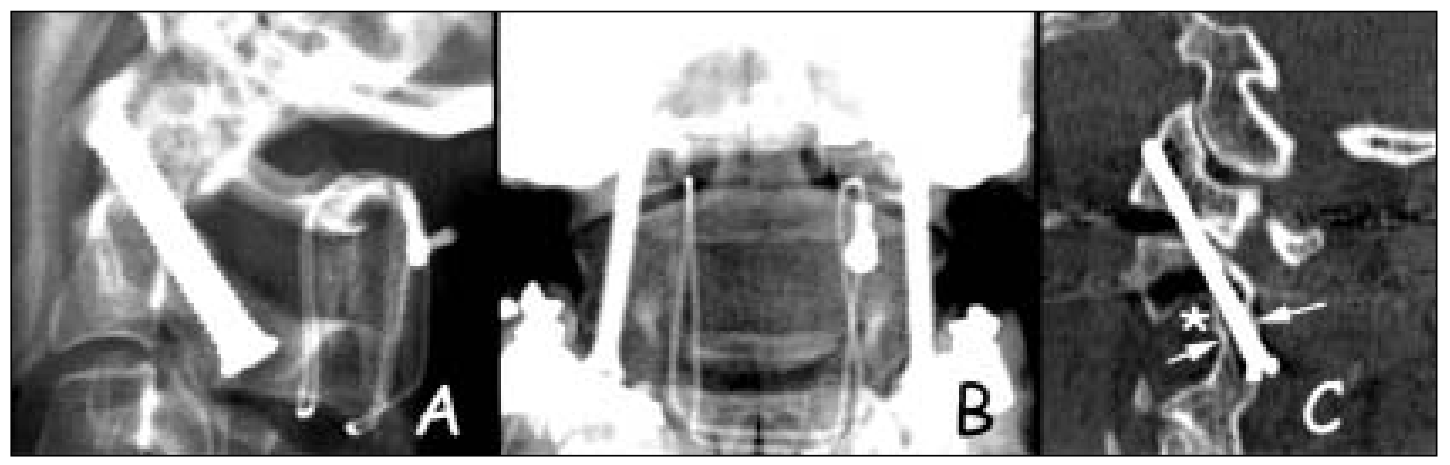

Figure 15: Lateral (A) and AP (B) plain x-rays of the final C1-2 transarticular screw construct with posterior fusion mass. Sagittal CT reconstruction $(C)$ showing one transarticular screw. The arrows indicate the width of the pars interarticularis; the asterisk indicates the vertebral artery foramen. 


\section{Conclusions}

Odontoid fractures are a common injury to the cervical spine. The classification scheme constructed by Anderson and D'Alonzo has proven useful with minor modifications. Type II and shallow type III odontoid fractures are most common and are often best treated with surgery. Of the surgical techniques available, direct anterior screw fixation appears to provide the best option chance for retention of the normal rotation of the cervical spine, a rapid return to normal lifestyle, and a high fusion rate if it is performed when the fracture is reasonably fresh (i.e., less than 6 months old). Remote fractures of the odontoid and os odontoideum should be treated with posterior C1-2 transarticular screw fixation with arthrodesis. Posterior fixation and fusion following transoral odontoid resection is used if ventral spinal cord compression is present, from irreducible chronic odontoid fractures. Because delayed neurologic compromise is a well-established danger of dens fractures, physicians should be aware of appropriate treatment measures.

\section{References}

1. Apfelbaum RI, Lonser RR, Veres R, Casey A. Direct anterior screw fixation for recent and remote odontoid fractures. J Neurosurg 2000;93:227-36.

2. Borne GM, Bedou GL, Pinaudeau M, Cristino G, Hussein A. Odontoid process fracture osteosynthesis with a direct screw fixation technique in nine consecutive cases. J Neurosurg 1988;68:223-6.

3. Dickson H, Engel S, Blum P, Jones RF. Odontoid fractures, systemic disease and conservative care. Aust N Z J Surg 1984;54:243-7.

4. Fujii E, Kobayashi K, Hirabayashi K. Treatment in fractures of the odontoid process. Spine 1988;13:604-9.

5. Greene KA, Dickman CA, Marciano FF, Drabier JB, Hadley MN, Sonntag VK Acute axis fractures. Analysis of management and outcome in 340 consecutive cases. Spine 1997;22:1843-52.

6. Husby J, Sorensen KH. Fracture of the odontoid process of the axis. Acta Orthop Scand 1974;45:182-92.

7. Paradis GR, Janes JM. Posttraumatic atlantoaxial instability: the fate of the odontoid process fracture in 46 cases. .J Trauma 1973;13:359-67.

8. Schatzker J, Rorabeck CH, Waddell JP. Fractures of the dens (odontoid process). An analysis of thirty-seven cases. J Bone Joint Surg Br 1971;53:392-405.

9. Crockard HA, Heilman AE, Stevens JM. Progressive myelopathy secondary to odontoid fractures: clinical, radiological, and surgical features. J Neurosurg $1993 ; 78: 579-86$.

10. Anderson LD, D'Alonzo RT. Fractures of the odontoid process of the axis. J Bone Joint Surg Am 1974;56:1663-74.

11. Scott EW, Haid RW Jr, Peace D. Type I fractures of the odontoid process: implications for atlanto-occipital instability. Case report. J Neurosurg. 1990;72:488-92

12. Henry AD, Bohly J, Grosse A. Fixation of odontoid fractures by an anterior screw. J Bone .Joint Surg Br 1999;81:472-7.

13. Crockard HA. Anterior approaches to lesions of the upper cervical spine. Clin Neurosurg 1988;34:389-416.

14. Deliganis AV, Baxter AB, Hanson JA, Fisher DJ, Cohen WA, Wilson A.J, et al. Radiologic spectrum of craniocervical distraction injuries. Radiographies $2000 ; 20: \mathrm{S} 237-50$.

15. Nepper-Rasmussen J. CT of dens axis fractures. Neuroradiology 1989;31:1046 .

16. Dickman CA, Sonntag VK. Injuries involving the transverse atlantal ligament: classification and treatment guidelines based upon experience with 39 injuries. Neurosurgery 1997;40:886-7.

17. Bucholz RW, Burkhead WZ, Graham W, Petty C. Occult cervical spine injuries in fatal traffic accidents. J Trauma 1979;19:768-71.

18. Huelke DF, O'Day .J, Mendelsohn RA. Cervical injuries suffered in automobile crashes. .J Neurosurg 1981;54:316-22.

19. Fairholm D, Lee ST, Lui TN. Fractured odontoid: the management of delayed neurological svmptoms. Neurosurgery 1996;38:38-43.

20. Bohlman HH. Acute fractures and dislocations of the cervical spine. An analysis of three hundred hospitalized patients and review of the literature. J Bone Joint Surg Am 1979;61:1119-42.
21. Moskovich R, Crockard HA. Myelopathy due to hypertrophic nonunion of the dens: case report. J Trauma 1990;30:222-5.

22. Sherk HH. Fractures of the atlas and odontoid process. Orthop Clin North Am 1978;9:973-84

23. Julien TD, Frankel B, Traynelis VC, Ryken TC. Evidence-based analysis odontoid fracture management. Neurosurg Focus 2000;8: Article 1.

24. Travnelis VC. Evidence-based management of type II odontoid fractures. Clin Neurosurg 1997;44:41-9.

25. Maiman DJ, Larson S.J. Management of odontoid fractures. Neurosurgery $1982 ; 11: 820$

26. Lind B, Nordwall A, Sihlbom H. Odontoid fractures treated with halo-vest. Spine $1987 ; 12: 173-7$

27. Apuzzo ML, Heiden JS, Weiss MH, Ackerson T'T, Harvey JP, Kurze T. Acute fractures of the odontoid process. An analysis of 45 cases. J Neurosurg. $1978 ; 48: 85-91$.

28. Ekong CE, Schwartz ML, Tator CH, Rowed DW, Edmonds VE. Odontoid fracture: management with early mobilization using the halo device. Neurosurgery $1981: 9 \cdot 631-7$.

29. Hadley MN, Browner C, Sonntag VK. Axis fractures: a comprehensive review of management and treatment in 107 cases. Neurosurgery 1985;17:281-90.

30. Wang GJ, Mabie KN, Whitehill R, Stamp WG. The nonsurgical management of odontoid fractures in adults. Spine 1984;9:229-30.

31. Brooks AL, Jenkins EB. Atlanto-axial arthrodesis by the wedge compression method. J Bone Joint Surg Am 1978;60:279-84.

32. Gallie W. Fractures and dislocations of the cervical spine. Am J Surg 1939;46:495-9

33. Dickman CA, Sonntag VK, Papadopoulos SM, Hadley MN. The interspinous method of posterior atlantoaxial arthrodesis. J Neurosurg 1991;74:190-8.

34. Jeanneret B, Magerl F. Primary posterior fusion C1/2 in odontoid fractures: indications, technique, and results of transarticular screw fixation. J Spinal Disord 1992;5:464-75.

35. Dickman CA, Sonntag VK. Posterior C1-C2 transarticular screw fixation for atlantoaxial arthrodesis. Neurosurgery 1998;43:275-81.

36. Gluf W, Schmidt M, Apfelbaum R. C1-2 transarticular screw fixation: a review of 191 adult patients with regard to surgical indication, fusion rate, complications, and lessons learned. .J Neurosurg Spine 2005;2:155-63.

37. Grob D, Jeanneret B, Aebi M, Markwalder TM. Atlanto-axial fusion with transarticular screw fixation. .J Bone Joint Surg Br 1991;73:972-6.

38. Marcotte P, Dickman CA, Sonntag VK, Karahalios DG, Drabier J. Posterior atlantoaxial facet screw fixation. J Neurosurg 1993;79:234-7.

39. Stillerman CB, Wilson .JA. Atlanto-axial stabilization with posterior transarticular screw fixation: technical description and report of 22 cases. Neurosurgery $1993 ; 32: 948-55$.

40. Apfelbaum RI Lasso cabling technique to achieve C1-2 posterior fusion in absence of $\mathrm{C} 1$ posterior arch. Joint Section on Disorders of the Spine and Peripheral Nerves AANS/CNS - tenth annual meeting 1994

41. Nakanishi T. Internal fixation of the odontoid fracture. Cent .Jpn .J Orthop Traumatic Surg 1980;23:399-406.

42. Apfelbaum RI. Anterior Screw Fixation of Odontoid Fractures: in Rengachary SS, Wilkins RH (eds). Neurosurgical Operative Atlas. $2^{\text {nd }}$ ed. Baltimore: Williams and Wilkins; 1992 . p. 189-99.

43. Bohler J. Anterior stabilization for acute fractures and non-unions of the dens. .J Bone Joint Surg Am 1982;64:18-27.

44. Esses SI, Bednar DA. Screw fixation of odontoid fractures and nonunions. Spine 1991;16:S483-5.

45. Geisler FH, Cheng C, Poka A, Brumback RJ. Anterior screw fixation of posteriorly displaced type II odontoid fractures. Neurosurgery 1989;25:30-8

46. Lesoin F, Biondi A, Jomin M. Foraminal cervical herniated dise treated by anterior discoforaminotomy. Neurosurgery 1987;21:334-8.

47. Aebi M, Etter C, Coscia M. Fractures of the odontoid process. Treatment with anterior screw fixation. Spine 1989;14:1065-70.

48. Apfelbaum RI. Neurosurgical operative atlas. Park Ridge, Ill. and Baltimore: American Association of Neurological Surgeons and Williams \& Wilkins; 1991.

49. Montesano PX, Juach EC, Anderson PA, Benson DR, Hanson PB. Biomechanic of cervical spine internal fixation. Spine 1991;16:S10-6.

50. Montesano PX, Anderson PA, Schlehr F, Thalgott JS, Lowrev G. Odontoid fractures treated by anterior odontoid screw fixation. Spine 1991;16:S33-7.

51. Dunn ME, Seljeskog EL. Experience in the management of odontoid process injuries: an analysis of 128 cases. Neurosurgery 1986;18:306-10.

52. Hadley MN, Browner CM, Liu SS, Sonntag VK. New subtype of acute odontoid fractures (type IIA). Neurosurgery 1988;22:67-71.

53. Hadley MN, Dickman CA, Browner CM, Sonntag VK. Acute axis fractures: a review of 229 cases. J Neurosurg 1989;71:642-7.

54. Mandabach M, Ruge JR, Hahn YS, McLone DG. Pediatric axis fractures: early halo immobilization, management and outcome. Pediatr Neurosurg 1993;19:225-32.

55. Odent T, Langlais J, Glorion C, Kassis B, Bataille J, Pouliquen JC. Fractures of the odontoid process: a report of 15 cases in children younger than 6 years. J Pediatr Orthop 1999;19:51-4

56. Sherk HH, Nicholson JT, Chung SM. Fractures of the odontoid process in young children. .J Bone .Joint Surg Am 1978;60:921-4.

57. Andersson S, Rodrigues M, Olerud C. Odontoid fractures: high complication rate 
associated with anterior screw fixation in the elderly. Eur Spine .J 2000;9:56-60.

58. Hanigan WC, Powell FC, Elwood PW, Henderson JP. Odontoid fractures in elderly patients. J Neurosurg 1993;78:32-5.

59. Lennarson PJ, Mostafavi H, Traynelis VC, Walters BC. Management of type II dens fractures: a case-control study. Spine 2000;25:1234-7.

60. Pepin JW, Bourne RB, Hawkins RJ. Odontoid fractures, with special reference to the elderly patient. Clin Orthop 1985:178-83.

61. Pitzen T, Caspar W, Steudel WI, Barbier D. [Dens fracture in elderly patients and surgical management]. Aktuelle Traumatol 1994;24:56-9.

62. Schaffler MB, Alson MD, Heller JG, Garfin SR. Morphology of the dens. A quantitative study. Spine 1992;17:738-43.

63. Jenkins JD, Coric D, Branch CL Jr. A clinical comparison of one- and two-serew odontoid fixation. J Neurosurg 1998;89:366-70.
64. Harms J, Melcher RP. Posterior C1-C2 fusion with polyaxial screw and rod fixation. Spine 2001;26:2467-71.

65. Goel A, Laheri V. Plate and screw fixation for atlanto-axial subluxation. Acta Neurochir Wien 1994;129:47-53.

66. Goel A, Desai KI, Muzumdar DP. Atlantoaxial fixation using plate and screw method: a report of 160 treated patients. Neurosurgery 2002;51:1351-6.

67. Goel A, Kulkarni AG, Sharma P. Reduction of fixed atlantoaxial dislocation in 24 cases:technical note. J Neurosurg Spine 2005;2:505-9.

68. Crockard HA, Calder I, Ransford AO. One-stage transoral decompression and posterior fixation in rheumatoid atlanto-axial subluxation. J Bone Joint Surg Br $1990 ; 72: 682-5$.

69. Chiba K, Fujimura Y, Toyama Y, Fujii E, Nakanishi T, Hirabayashi K. Treatment protocol for fractures of the odontoid process. J Spinal Disord 1996;9:267-76 